\title{
ECLAPMSIA: THE MAJOR CAUSE OF MATERNAL MORTALITY IN EASTERN INDIA
}

\author{
Ratan Das $^{1}$, Saumya Biswas ${ }^{2}$
}

\begin{abstract}
BACKGROUND: Eclampsia is a very serious complication of pregnancy which is responsible for high maternal and perinatal mortality. Worldwide, it accounts for 50,000 maternal deaths annually. In spite of several global and regional interventions and initiatives from governments and other concerned agencies, maternal mortality is still very high in India, with eclampsia as a major cause. This study was conducted to determine the mode of deaths and incidence of maternal mortality associated with eclampsia and to assess how socio-demographic and clinical characteristics of the women influence the deaths.

MATERIALS AND METHODS: This is a retrospective study of 111 eclampsia related maternal deaths over a period of 5 years from January 2008 to December 2012. Data pertaining to their age, parity, booking status, gestational age at delivery, and time interval from admission to death were also obtained from the records for analysis.

RESULTS: Eclampsia accounted for $43.35 \%$ of total maternal deaths, with case fatality of $4.960 \%$. The commonest mode of death in eclampsia is pulmonary oedema. Death due to eclampsia commonly occurs in younger age group of 19-24 years and in primi gravid. Eclampsia related deaths were mostly seen in illiterate and unbooked cases. Maternal deaths were also very common in lower socio economic status.

CONCLUSION: Eclampsia still remains the major cause of maternal mortality in this region resulting from unsupervised pregnancies and deliveries. There is a need to educate and encourage the general public for antenatal care and hospital delivery by which we can defeat this powerful enemy.
\end{abstract}

KEYWORDS: Eclampsia; Matetnal mortality; Case fatality; Rural India

DOI: http://dx.doi.org/10.4314/ejhs.v25i2.2

\section{INTRODUCTION}

Maternal mortality is defined as the death of any woman while pregnant or within 42 completed days of termination of pregnancy, irrespective of the duration or site of pregnancy, from any cause related to or aggravated by pregnancy, but not from accidental or incidental causes $(1,2)$. Pregnancy, although considered a physiological state, carries risk of serious maternal morbidity and at times of death. Eclampsia is a very serious complication of pregnancy responsible for high maternal and perinatal mortality. Eclampsia is an acute and life-threatening complication of pregnancy characterized by the appearance of tonic clonic seizures (convulsions), usually in a woman who has developed pre-eclampsia. Eclampsia includes convulsions and coma that happen during pregnancy but are not due to preexisting or organic brain disorder. Eclampsia related complications include CVA (cerebro vascular accident), pulmonary oedema, renal failure, HELLP (haemolysis, elevated liver enzyme, and low platelet count) syndrome, DIC (Disseminated Intravascular Coagulation) and hepatic failure (3).

Maternal mortality is an index to judge the health care by a country to the women population. It also reflects the educational and

\footnotetext{
${ }^{1}$ Department of Obstetrics and Gynaecology, Malda Medical College and Hospital, Malda, West Bengal, India

${ }^{2}$ Department of Anaesthesiology, Malda Medical College and Hospital, Malda, West Bengal, India

Corresponding Author: Ratan Das, Email: ranta1982@gmail.com
} 
socio-economic state of a country as well as public health consciousness. Between 1990 and 2010, maternal mortality worldwide dropped by almost $50 \%$ but is still unacceptably high. Almost all maternal deaths (99\%) occur in developing countries $(1,2)$. India is among those countries, which has a very high maternal mortality ratio. The high number of maternal deaths in some areas reflects inequities in access to health services, and highlights the gap between the rich and the poor $(4,5,6)$. Despite the several global and regional interventions and initiatives from governments and other concerned agencies, maternal mortality continues to be very high in Sub-Saharan Africa and India, with eclampsia as a major cause. In developed countries with effective antenatal screening programmes, advanced diagnostic and therapeutic intervention and extensive research, the disease has become a rare complication of pregnancy. Unfortunately, such changes have not occurred in developing countries and eclampsia continues to be a very serious problem $(7,8,9$, 10). Two major causes of maternal death in India are haemorrhage and eclampsia. This is also the major cause of maternal mortality in eastern part of India. The present study was undertaken to determine the incidence of maternal mortality associated with eclampsia and to assess how socio-demographic and clinical characteristics of the women influence the deaths. This study was also done to assess the mode of death in eclampsia in rural area of Eastern India.

\section{MATERIALS AND METHODS}

This retrospective hospital based study was carried out in the Malda Medical College and Hospital, a rural tertiary level health care referral centre in West Bengal of Eastern India. The study was conducted over a period of 5 years from January 2008 to December 2012. Out of total 256 maternal deaths recorded over the study period, we retrieved 111 patients who died due to eclampsia from the medical records section of Malda Medical College and Hospital. Data pertaining to their age, parity, booking status, gestational age at delivery, and time interval from admission to death were also obtained from the records for analysis. In the study period, all eclmapsia cases were treated with magnesium sulphate. The pregnant women with known seizure disorder were excluded from our study. Eclamptic mothers who did not have magnesium sulphate were also excluded from the study. This study was approved by institutional ethics committee.

\section{RESULTS}

In the present study, out of 52413 deliveries, there were 256 maternal deaths, giving a MMR of 518.48 per 1,00,000 live births, which is higher than the national averages. Out of 256 maternal deaths, 111 were eclapmsia related. The most common causes of maternal mortality in our study are eclampsia $(43.35 \%)$, haemorrhage $(21.87 \%)$, sepsis $(13.28 \%)$, heart disease $(6.64 \%)$, pulmonary embolism $(2.73 \%)$ etc.

It is seen that the majority of maternal deaths belonged to lower socio-economic class and those who are illiterate (Table 1). Furthermore, almost all mothers who died were from rural areas (Table $1)$.

Table 1: Distribution of maternal deaths $(\mathrm{n}=111)$ according to socio demographic characteristics

\begin{tabular}{llllll}
\hline Variables & 2008 & 2009 & 2010 & 2011 & 2012 \\
\hline Socio economic status & & & & & \\
$\quad$ Upper & 0 & 0 & 0 & 0 & 0 \\
$\quad$ Middle & 2 & 3 & 4 & 3 & 4 \\
$\quad$ Lower & 16 & 15 & 22 & 20 & 22 \\
Education & 15 & 14 & 19 & 18 & 20 \\
$\quad$ Illiterate & 2 & 3 & 5 & 4 & 4 \\
$\quad$ Primary education & 1 & 1 & 2 & 1 & 2 \\
$\quad$ Secondary education & 0 & 0 & 0 & 0 & 0 \\
$\quad$ Higher Secondary education & 1 & 0 & 0 & 0 & 0 \\
Area of residence & 17 & 18 & 26 & 23 & 26 \\
$\quad$ Urban & & & & & \\
$\quad$ Rural & & &
\end{tabular}


Age and parity distribution in eclamptic mothers

below 24 years $(76.57 \%)$ and primi gravidas who died during the study period shows that age

$(61.26 \%)$ were commonly affected (Table 2$)$.

Table 2: Age and Parity distribution in eclamptic mothers who died $(\mathrm{n}=111)$ during the study period (20082012)

\begin{tabular}{llllllll}
\hline Variables & 2008 & 2009 & 2010 & 2011 & 2012 & Total & Percentage (\%) \\
\hline Age & & & & & & & \\
$\quad<19$ & 6 & 6 & 9 & 8 & 7 & 36 & $32.4 \%$ \\
$19-24$ & 8 & 6 & 10 & 11 & 14 & 49 & $44.1 \%$ \\
$25-29$ & 3 & 3 & 3 & 2 & 1 & 12 & $10.8 \%$ \\
$30-34$ & 1 & 2 & 3 & 2 & 2 & 10 & $9.0 \%$ \\
$>35$ & 0 & 1 & 1 & 0 & 2 & 4 & $3.6 \%$ \\
Parity & & & & & & & \\
Primigravida & 11 & 12 & 16 & 14 & 15 & 68 & $61.3 \%$ \\
Multigravida (2-4) & 6 & 5 & 9 & 8 & 8 & 36 & $32.4 \%$ \\
Grand multi (>4) & 1 & 1 & 1 & 1 & 3 & 7 & $6.3 \%$ \\
\hline
\end{tabular}

Maximum maternal deaths were seen in unbooked in the 3rd trimester and within 12 hours of cases (Table 3). The majority of deaths occurred admission (Table 3).

Table 3: Distribution of maternal deaths by delivery related characteristics

\begin{tabular}{lllllll}
\hline Variables & 2008 & 2009 & 2010 & 2011 & 2012 & Percentage \\
\hline Booking & 1 & 2 & 2 & 2 & 4 & $9.91 \%$ \\
$\quad$ Booked & 17 & 16 & 24 & 21 & 22 & $90.09 \%$ \\
$\quad \begin{array}{l}\text { Unbooked } \\
\text { Stage of pregnancy at time of death }\end{array}$ & 2 & 1 & 2 & 1 & 1 & $6.31 \%$ \\
$\quad 2^{\text {nd }}$ trimester & 12 & 13 & 17 & 16 & 19 & $69.37 \%$ \\
$3^{\text {rd }}$ trimester & 4 & 4 & 7 & 6 & 6 & $24.32 \%$ \\
$\quad$ Post partum & 7 & 8 & 10 & 9 & 11 & $40.54 \%$ \\
Time interval from admission to death & & & & & \\
0-6 hrs & 5 & 6 & 9 & 8 & 9 & $33.33 \%$ \\
$7-12$ hrs & 4 & 3 & 5 & 4 & 3 & $17.12 \%$ \\
13-24 hrs & 2 & 1 & 2 & 2 & 3 & $9.01 \%$ \\
$>24$ hrs & & & & & & \\
\hline
\end{tabular}

When we analyzed the maternal mortality, it is contributes $43.35 \%$ of total maternal deaths (Table seen that, during the study period eclampsia 4).

Table 4: Year wise incidence of maternal mortality due to eclampsia in 5 years study period (2008-2012)

\begin{tabular}{|c|c|c|c|c|c|c|}
\hline Maternal death & 2008 & 2009 & 2010 & 2011 & 2012 & $\begin{array}{l}\text { Total during } \\
\text { study period }\end{array}$ \\
\hline Maternal Deaths & 40 & 40 & 62 & 54 & 60 & 256 \\
\hline Deaths due to eclampsia & 18 & 18 & 26 & 23 & 26 & 111 \\
\hline $\begin{array}{l}\text { Contribution to maternal deaths due to } \\
\text { eclampsia }\end{array}$ & $45 \%$ & $45.0 \%$ & $41.9 \%$ & 42.6 & $43.3 \%$ & $43.4 \%$ \\
\hline
\end{tabular}


Overall incidence of eclampsia in our 5 years' rate during the study period was $4.960 \%$ (Table 5). study period was $2.102 \%$, and overall case fatality

Table 5: Incidence of eclampsia and case fatality rate during the study period (2008-2012)

\begin{tabular}{lllllll}
\hline Year & $\begin{array}{l}\text { Total no of } \\
\text { delivery (n) }\end{array}$ & $\begin{array}{l}\text { Total no of } \\
\text { eclampsia(m) }\end{array}$ & $\begin{array}{l}\text { Eclampsia } \\
\text { deaths (p) }\end{array}$ & $\begin{array}{l}\text { Incidence } \\
\text { eclampsia } \\
=\mathrm{m} / \mathrm{n} \%\end{array}$ & $\begin{array}{l}\text { of } \\
\text { (i) }\end{array}$ & $\begin{array}{l}\text { Case fatality rate } \\
(\mathrm{f})=\mathrm{p} / \mathrm{m} \%\end{array}$ \\
\hline 2008 & 8614 & 225 & 18 & $2.612 \%$ & $8 \%$ \\
2009 & 9077 & 240 & 18 & $2.644 \%$ & $7.50 \%$ \\
2010 & 10454 & 280 & 26 & $2.678 \%$ & $9.285 \%$ \\
2011 & 12256 & 320 & 23 & $2.610 \%$ & $7.187 \%$ \\
2012 & 12012 & 312 & 26 & $2.597 \%$ & $8.333 \%$ \\
Total & 52413 & 1377 & 111 & $2.627 \%$ & $8.061 \%$ \\
\hline
\end{tabular}

In our study, the analysis of mode of maternal deaths in eclampsia showed that pulmonary oedema was the commonest mode of death (Table $6)$.

Table 6: Mode of maternal deaths in eclamptic mother $(\mathrm{n}=111)$ who died during the study period (2008-2012)

\begin{tabular}{lllll}
\hline Year & $\begin{array}{l}\text { Pulmonar } \\
\text { y oedema }\end{array}$ & CVA & $\begin{array}{l}\text { Renal } \\
\text { failure }\end{array}$ & Others \\
\hline 2008 & 10 & 6 & 2 & 0 \\
2009 & 9 & 8 & 1 & 0 \\
2010 & 17 & 7 & 2 & 0 \\
2011 & 15 & 7 & 1 & 0 \\
2012 & 14 & 11 & 3 & 2 \\
\hline
\end{tabular}

\section{DISCUSSION}

Maternal mortality is unacceptably high in developing countries including India. Death of mothers is a tragic event. In practical life, it has a severe impact on the family, community and eventually, the nation. The young surviving children left motherless are unable to cope with daily living and are at an increased risk of death. Reduction of maternal mortality is the objective of MDGs, especially in low income countries, where one in 16 women die of pregnancy related complications (11).

Hypertensive disorders of pregnancy are a major cause of maternal and fetal morbidity and mortality all over the world. Eclampsia is a well recognized complication of hypertensive disorders of pregnancy $(7,8,9)$. In the developed countries like UK, eclampsia is rare, but in developing countries, the prevalence has been estimated to be up to 20 times higher. Of the estimated 600,000 women worldwide who die each year of pregnancy related complications, more than 50,000 die of preeclampsia or eclampsia, and $99 \%$ of these deaths occur in developing countries (1, 2).

In the present study, there were 256 maternal deaths out of 52413 deliveries, giving a MMR of 518.48 per $1,00,000$ live births. This MMR is much higher than the national averages which is 212 per 1,00,000 live births. Malda Medical College and Hospital, being a teaching institution and a tertiary care centre, receives complicated cases from rural areas. Admissions of moribund cases referred from peripheral hospitals have inflated this mortality ratio, like in other teaching institutions of India. Similar studies from tertiary care institution by Pal et al (12), Purandare et al (13) and Verma et al (14) also reported MMR between 213 to 879 per 1,00,000 live births.

Majority of patients in the present study belong to low socio-economic group and were illiterate (Table 1). Most of them were from rural areas, had no antenatal visit and presented late with complication of eclampsia. It favours the observation that education, good antenatal care, early referral to intensive care units for standard care can reduce its incidence and complications. Due to lack of awareness, people do not seek medical advice at an early stage. As the majority of masses belong to low socio-economic group, they do not report to hospitals even in late stages. It is, therefore, reasonable to assume that quite a large number of patients die at home without getting to hospital. This is also comparable to other Indian studies $(15,16)$.

Age and parity distribution (Table 4) of eclamptic mother shows that age below 24 years 
(76.57\%) was commonly affected. It is also seen from the present study that maximum maternal deaths occurred in primi gravidas $(61.26 \%)$. This is comparable with another Indian study (17). In our study, eclampsia related deaths were mainly seen in younger age group and in primi gravidas. This is because of early marriage and early pregnancy. In rural India, due to social customs, teenage pregnancy is a very common practice. Low socio-economic status and illiteracy are also important causes of early marriage and child birth (17).

The majority of deaths in our study were in the late third trimester (ante partum) (Table 5). Maximum deaths occurred within 12 hours of admission (73.87\%) and in unbooked $(90.09 \%)$ cases (Table 3). This is mainly due to late referral, poor antenatal check up and transfer of moribund patients just before death to the tertiary hospital. A study done by Berhan et al also supports our findings (18).

Previously, obstetric haemorrhage was the major cause of maternal mortality in India at primary, secondary and tertiary care setups. However, recently, paradigm shift has been observed in tertiary health care setup like medical colleges. In our study, it was observed that eclampsia contributes to $43.57 \%$ (Table 4) of all maternal deaths, whereas eclampsia causes $12 \%$ of all global maternal deaths (1,2). A study from Eastern India (West Bengal) by Sarkar et al also supports our result (19).

In our study, incidence of eclampsia is $2.627 \%$, and case fatality is $8.061 \%$ (Table 5). Similar incidence of eclampsia was also published in other Indian studies $(20,21,22)$. A study by Nobis also published similar case fatality rate like our study did (23).

While reviewing the mode of deaths in eclampsia, it was observed that pulmonary oedema is the commonest cause of death in eclampsia in our study (Table 6). Incidence of pulmonary oedema is higher in eclampsia due to leaky pulmonary capillaries. In our setup, due to lack of intensive care monitoring, poorly monitored fluid therapy due to lack of central venous pressure monitoring and pulmonary capillary wedge pressure monitoring leads to increased risk of pulmonary oedema. Lack of ventilatory support is another cause of increased incidence of maternal mortality in pulmonary oedema in our study. In UK, commonest cause of death in eclampsia is CVA which is different from our study $(24,25)$.

The results of this study depicted a pitiful and gloomy picture of our society. Analysis of every maternal death through maternal death audit, either at community level (verbal autopsy) or at the institutional level should be carried out. It will help in identifying the actual cause of maternal deaths and deficiencies in health care delivery system that might contribute to formulating preventive measures to reduce pregnancy related deaths.

Eclampsia contributes significantly to maternal mortality in India. Efforts should be made by all concerned to improve facilities and social infrastructures that will directly or otherwise minimize the occurrence of eclampsia. To reduce the maternal mortality and morbidity, the main thrust should be on implementing basic and comprehensive emergency obstetrics care. Most deaths can be avoided by improving socioeconomic status, level of education, quality of patients' nutrition, good antenatal, intrnatal and postnatal care, early referral, and quick and well equipped transport facilities.

\section{REFERENCES}

1. Countdown to 2015 for maternal, newborn and child survival: accountability for maternal, newborn and child survival. Geneva: World Health Organisation, 2013 (http//www.countdown2015mnch.org/docume nts/2013Report/Countdown_2013-

Updates_noprofiles.pdf).

2. Trends in maternal mortality: 1990-2010 estimates developed by WHO, UNICEF, UNFPA and the World Bank. 2012.

3. Micheal BB. Eclampsia. Emer Med J, 2000; 74: $1-10$.

4. World Health Organization \& Unicef. Countdown to 2015 Decade Report (2000-2010): Taking Stock of Maternal, Newborn and Child Survival. Geneva: WHO and

UNICEF, 2010 [http//www.childinfo.org/files/ countdownReport 2000-2010.pdf] Accessed 17 August 2011.

5. Bangal VB, Giri PA, Garg R. Maternal Mortality at a Tertiary Care Teaching Hospital 
of Rural India: A Retrospective Study. Int J Biol Med Res, 2011;2(4): 1043 - 1046.

6. Mullick SS, Serle E. Achieving millennium development goals 4 and 5: a snapshot of life in rural India BJOG. 2011;118 (Suppl. 2):104107.

7. Goldenberg RL, McClure EM, MacGuire ER, et al. Lessons for low-income regions following the reduction in hypertensionrelated maternal mortality in high-income countries. Int J Obstet Gynecol. 2011; 113:9195.

8. Danso KA, Opare-Addo HS. Challenges associated with hypertensive disease during pregnancy in low-income countries. Int $J$ Obstet Gynecol, 2010;110:78-81.

9. Dasari P, Habeebullah S. Maternal mortality due to hypertensive disorders of pregnancy in a tertiary care center in Southern India. Int $J$ Obstet Gynaecol, 2010;110:271-273.

10. Engle PL, Fernald LC, Alderman H, et al. Strategies for reducing inequalities and improving developmental outcomes for young children in low-income and middle-income countries. Lancet, 2011;378:1339-1353.

11. Gurina NA, Vangen S, Forsen L, Sundby J. Maternal mortality in St. Petersburg, Russian Federation. Bull World Health Organization, 2006; 84: 283-9.

12. Pal A, Rai P, Hazara S, Mondal T K. Review of changing trends in Maternal Mortality in rural medical College in West Bengal. $J$ Obstet Gynaecol India. 2005; 55: 521-525.

13. Purandare N, Singh A, Upahdya S, et al. Maternal mortality at a referral centre: a five year study. J obstet Gynaecol India, 2007; 57(3):248-50.

14. Verma A, Minhas S, Sood A. A study of Maternal Mortality. J Obstet Gynaecol India. 2008; 58: 226-229.

15. Yaliwal RG, Jaju PB, Vanishree M. Eclampsia and Perinatal Outcome: A Retrospective Study in a Teaching Hospital. J of Clin and Diagn Res, 2011;5(5):1056-1059.

16. Kaur P. A clinical study in eclampsia on a referral hospital. J South Asian Feder Obst Gnaecol, 2012;4(2):113-115.
17. Dutta MR, Pant L, Kabiraj M, Basu SB. Magnesium sulphate in eclampsia: A safe, efficient and cost effective approach: $J$ Obstet Gynecol Ind, 2002; 52(3) 65-68.

18. Berhan Y, Berhan A. Reasons for persistently high maternal and perinatal mortalities in Ethiopia: Part III - Perspective of the "Three delays" model Health system factors. Ethiop $J$ Health Sci, 2014; Special issue 1.

19. Sarkar M, Basak S, Mondal SK, Das S, Roy D, Mandal J, Mondal SC, Das SK. Maternal mortality associated with eclampsia in an Indian medical college: a four year retrospective study. $J$ Med Med Sci, 2013;4(10):394-398.

20. Saha S, Ghosh S, Ganguly RP, Das A. Comparative study of efficacy of magnesium sulphate and diazepam in the management of eclampsia in a peripheral rural medical college (A cross over study of 440 cases). J Obstet Gynecol Ind, 2002; 52: 69-72.

21. Majhi AK, Chakraborty PS, Mukhopadhyay A. Eclampsia - Present scenario in a Referral Medical College Hospital. J Obstet Gynecol Ind, 2001; 51: 143-147.

22. Kamilya G, Bhattacharya SK, Mukherjee J. Changing trends in the management of eclampsia from a teaching hospital. JIMA, 2005; 103: 132-135.

23. Nobis PN. Maternal outcome in eclampsia. $J$ Obstet Gynecol Asia, 2002; 6: 25-28.

24. Tuffnell DJ, Jankowicz D, Lindow SW, Lyons G, Mason GC, Russell IF, et al. Outcomes of severe preeclampsia / eclampsia in Yorkshire 1999/2003. Br. J Obstet Gynecol, 2005; 112: 875-80.

25. Lewis G, ed. Confidential Enquiry into Maternal and Child Health (CEMACH). Saving Mothers' Lives: Reviewing Maternal Deaths to Make Motherhood Safer-20032005. The Seventh Report on Confidential Enquiries into Maternal Deaths in the United Kingdom. London: CEMACH, 2007. Available from http://www.cmace.org.uk (accessed 2 June 2011) 